\title{
Association of bovine Toll-like receptor 4 with tick infestation rates and blood histamine concentration
}

\author{
G. Zhao ${ }^{1,2}$, M. Yu' ${ }^{1}$ Q.-W. Cui' ${ }^{2}$ X. Zhou ${ }^{2}$, J.-C. Zhang1, H.-X. Li' \\ K.-X. Qu ${ }^{1,3}$, G.-L. Wang ${ }^{2}$ and B.-Z. Huang ${ }^{1}$ \\ ${ }^{1}$ Yunnan Academy of Grassland and Animal Science, Kunming, China \\ ${ }^{2}$ College of Animal Science and Technology, Nanjing Agricultural University, \\ Nanjing, China \\ ${ }^{3}$ College of Animal Science and Technology, Northwest A\&F University, \\ Yangling, Shaanxi, China \\ Corresponding authors: G.-L. Wang / B.-Z. Huang \\ E-mail: glwang@njau.edu.cn / hbz@ynbp.cn
}

Genet. Mol. Res. 12 (3): 2783-2793 (2013)

Received April 23, 2012

Accepted November 22, 2012

Published February 28, 2013

DOI http://dx.doi.org/10.4238/2013.February.28.21

ABSTRACT. We investigated a possible association between bovine
Toll-like receptor 4 (TLR4) and resistance to tick infestation in 103
cattle, including BMY cattle (1/2 Brahman, 1/4 Murray Grey, and $1 / 4$
Yunnan Yellow cattle), Brahman, and Red Angus grazing on improved
pasture. The tick infestation weight and number of Rhipicephalus
microplus and the blood histamine concentration were measured and
compared with those of 32 Chinese Holsteins and 30 Simmentals.
A 228 -bp fragment was amplified and sequenced to analyze the
polymorphisms of the TLR 4 gene. After SSCP and sequencing analysis,
4 SNPs, i.e., 535(A $>C), 546(T>C), 605(T>A)$, and $618(\mathrm{G}>\mathrm{C})$, were
identified, corresponding to GenBank accession Nos. AY297041 and
NW_003104150; the latter two SNPs caused Leu $\rightarrow \mathrm{Gln}$ and Gln $\rightarrow$ His
substitutions, respectively. Genotype AA was completely predominant
in the Chinese Holstein and Simmental; genotypes AA and AB were
detected in Red Angus, while genotypes AA, AB, BB, and BC were 
detected in Brahman and in BMY cattle. A negative correlation was identified between blood histamine concentration and number of tick infestation; in BMY cattle this negative association was significant. The tick infestation in cattle with genotype BB was significantly lower than in those with genotype AA. Blood histamine concentration in cattle with genotype BB was significantly higher than in those with genotype AA. The TLR4 gene mutation could affect the blood histamine level and activate the immune reaction after tick infestation. Allele B has potential as a molecular marker for tick-resistance originated from Zebu cattle for use in cattle breeding programs.

Key words: TLR4 gene; Tick; Rhipicephalus microplus; Histamine; Brahman; BMY cattle

\section{INTRODUCTION}

As a type of blood-sucking ectoparasite, ticks cause seriously economic losses in farm animals via and tick-borne disease. The widespread prevalence of the ixodid Rhipicephalus microplus is one of the main contributors to the losses in the grassland animal-raising business (Bechara et al., 2000; Gao et al., 2004). To obtain a blood meal, this ixodid must attach to the skin of its host and sustain an ingestion of blood for 1 to 2 consecutive weeks. Hematophagia expands the organism to 100 -fold its original size. Consecutive bites increase the risk of a complicated immune response, including that of the tick, the transmitted pathogen to the host, and a subsequent immunological rejection of the pathogen from the host (Zhao and Kong, 2000; Andreotti et al., 2002; Maritz-Olivier et al., 2007). Acquired anti-tick immunity can fight the tick to decrease blood-sucking volume, attachment time, number of engorged ticks, and the capacity of female ticks to lay eggs. Obvious pathological changes such as inflammatory response are likely found at the bite site on cattle surfaces.

Breeding and developing a new beef cattle type with strong tick resistance by introducing the Zebu ancestry into local cattle is one of the most effective approaches to controlling tick infestation (Gao et al., 2004). Brahman cattle are a type of Zebu, and many studies have proven that Zebu display anti-tick capabilities stronger than those of other local cattle (O'Kelly and Spiers, 1976; Zhao and Kong, 2000), confirming that Brahman can be considered a preferable paternal line for a crossbreeding program. The staff at the Academy of Grassland and Animal Science of Yunnan Province has been using Brahman as a paternal resource for crossbreeding with Murray Grey and Yunnan Yellow cattle since the 1980s and has developed BMY cattle - a 3-way beef breed with genetic components consisting of one-half Brahman, one-fourth Murray Grey, and one-fourth Yunnan Yellow cattle. Presently, BMY cattle are being bred inter se and display high growth rate, adequate meat quality, heat-resistance, and most important, strong tick-resistance (Wen, 1996; Wen et al., 2003). The formation of BMY cattle is a beautiful example of the introduction of the Zebu bloodline to crossbreed a new beef breed in South China (Qu et al., 2006, 2007, 2012; Yang et al., 2011).

Toll-like receptors (TLRs) are important pathogen recognition receptors that activate innate and adaptive immune responses (Aderem and Ulevitch, 2000; White et al., 2003). Various pathogen infections trigger inflammatory responses by activating TLR signaling 
molecules, which build specific immunity by providing stimulating factor and cytokineinducing T-cell differentiation and releasing mediators of inflammation. Notably, the TLR4 gene seems to play an important role in immune responses because TLR4 expression remarkably increases around infected foci. The bovine TLR4 gene is located on chromosome 8 , which has led to speculation that it is associated with bovine anti-tick capability (White et al., 2003; McGuire et al., 2006).

Researchers have also proven the existence of gland biofactors that function in vasodilatation and immunity regulation in the salvia of ticks. These biofactors may inhabit the maturation of dendritic cells. Stimulated dendritic cells generate lipopolysaccharide, the ligand of $T L R 4$, and ultimately weaken host immunity, making them more sensitive to tick infestation (Oliveira et al., 2010). TLR2-deficit mice are more sensitive to Mycobacterium tuberculosis, and the capacity of TLR4-deficit mice to eradicate M. tuberculosis significantly declines in chronic infection, suggesting a domain function for TLR 4 in chronic infection (Abel et al., 2002; Reiling et al., 2002). The widespread mutation of the human TLR4 gene might influence the ectodomain of the TLR gene so that the inhalation of lipopolysaccharide does not lead to hyperresponsiveness (Arbour et al., 2000). These results strongly support the hypothesis that $T L R$ genotypes are associated with the individual sensitivity to disease, but limited information is available about the association of tick infestation with bovine TLR genotypes and blood histamine concentration (BHC). The present study focused on the associations of the TLR4 gene with tick resistance in BMY cattle to explore the candidate gene associated with tick resistance via molecular markers in beef crossbreeding processes.

\section{MATERIAL AND METHODS}

\section{Experimental animals and location}

Experiments using $R$. microplus were performed on Xiaoshao farm in Kunming, Yunnan Province, China $\left(25.3667^{\circ} \mathrm{N}, 102.7433^{\circ} \mathrm{E}\right.$; altitude of $1980 \mathrm{~m}$; average temperature of $14.7^{\circ} \mathrm{C}$ in 2009), in which $R$. microplus parasitizes the surfaces of cattle year round. The heaviest infestations occur between June and September. Ticks were counted from November 6 to December 27, 2009, when Stomoxys calcitrans are reduced to avoid interfering factors. The average temperature during the experiment was $9.7^{\circ} \mathrm{C}$, and the relative humidity was $72.5 \%$ during the fieldwork.

Healthy adult cattle were randomly grouped and included 30 Brahmans (introduced from Australia in 1997), 34 BMY cattle, 9 Red Angus (introduced from Australia in 2002) from more than 400 Brahman and 450 BMY cattle, feeding freely under 24-h grazing conditions on an improved pasture. Thirty Simmental (introduced from Canada in 1996, from a geographical zone without $R$. microplus infestation) from another farm in Xiaoshao, and 32 Chinese Holstein in feedlot conditions in Nanjing, Jiangsu Province, were selected as controls to investigate the polymorphisms of the TLR4 gene.

\section{Quantification of $\boldsymbol{R}$. microplus infestation}

The experimental animals fed freely under 24-h grazing condition on an improved pasture with a history of tick infestation, and the animals naturally acquired ticks. Routine 
observation was carried out to ensure the presence of ticks on the bodies of the animals every day. On November 6, 2009, after 35 days under the described grazing conditions, the experimental animals were sprayed with 1:400 chemical acaricide (Diazinon, $\mathrm{C}_{12} \mathrm{H}_{21} \mathrm{~N}_{2} \mathrm{O}_{3} \mathrm{PS}$, Hebei Kexing Pharmaceutical Co., Ltd.), and ticks were assumed to be killed and the cattle surfaces to be free of tick infestation. Our count was carried out after the spraying when fully engorged ticks appeared on the bodies of the cattle. All larval ticks were counted, and fully engorged and half-engorged ticks were collected and weighed by hand once every 2 days for a total of 7 counts. The data included the amount of natural larval tick infestation from days 35 to 50 and the number and weights of fully engorged and half-engorged ticks every 2 days.

\section{Determination of $\mathrm{BHC}$ in bovine venous blood}

After the last count of $R$. microplus on day 50 of the experimental period, blood samples were collected from the cattle population. After the preparation of the antibody/antigen/ enzyme-linked antibody complex, tetramethylbenzidine substrate solution was added. The substrate turned blue when horseradish peroxidase was catalyzed, and the reaction was then terminated via the addition of sulfuric acid solution, changing the color to yellow. Optical density (OD) values were measured spectrophotometrically at a wavelength of $450 \mathrm{~nm}$. The BHC of the samples was determined by comparing the OD values of the samples with the standard curve. Assay width ranged from 0.75 to $15.0 \mu \mathrm{g} / \mathrm{L}$. The correlation parameter $r^{2}$ value between the $\mathrm{OD}$ value and $\mathrm{BHC}$ was estimated.

\section{DNA extraction}

Jugular venous blood was collected into tubes containing heparin sodium after the last $R$. microplus count was completed. The blood samples were stored at $-20^{\circ} \mathrm{C}$. DNA was isolated using a conventional phenol-chloroform method (Ausubel et al., 1995).

\section{Polymerase chain reaction (PCR) and single-strand conformation polymorphism (SSCP) analysis}

Specific primers (forward, 5'-CCAGGATGATGGCGCGTGC-3'; reverse, 5'-GATTCCT GCGGTTTCTTAC-3') were designed according to the bovine TLR4 gene in GenBank (accession Nos. AY297041 and NW_003104150) and synthesized by Nanjing Jinsirui Biotechnology Co., Ltd. PCR was performed in a volume of $15 \mu \mathrm{L}$ containing $50 \mathrm{ng}$ genomic DNA, $1 \mu \mathrm{L} 5$ pmol of each primer, $1 \mu \mathrm{L} 10 \mathrm{mM}$ deoxyribonucleotide triphosphates, $2.5 \mu \mathrm{L} 10 \mathrm{X}$ PCR buffer with $1.5 \mathrm{mM} \mathrm{MgCl}$ final concentration, and $0.5 \mathrm{U}$ Taq DNA polymerase. PCR was performed using an initial predenaturation for $5 \mathrm{~min}$ at $95^{\circ} \mathrm{C}$ followed by 30 cycles of $1 \mathrm{~min}$ at $94^{\circ} \mathrm{C}, 1$ min at $57^{\circ} \mathrm{C}$, and $1 \mathrm{~min}$ at $72^{\circ} \mathrm{C}$, with a final extension of $10 \mathrm{~min}$ at $72^{\circ} \mathrm{C}$. $\mathrm{PCR}$ products were checked on $1.0 \%$ agarose gel. Then, $5 \mu \mathrm{L}$ of each PCR product was mixed with $5 \mu \mathrm{L}$ denaturing buffer ( $95 \%$ formamide, $25 \mathrm{mM}$ ethylenediaminetetraacetic acid, $0.025 \%$ xylene cyanole, and bromophenol blue), denatured at $98^{\circ} \mathrm{C}$ for $10 \mathrm{~min}$, and chilled on ice immediately for 5 to 10 min. SSCP analysis was performed to electrophorese the denatured mixture for 10 to $12 \mathrm{~h}$ on $12 \%$ polyacrylamide gel with silver nitrate staining. SSCP bands were photographed and recorded, and genotypes were defined according to the band patterns. Some of the PCR products 
were directly sequenced after purification to identify genotypes using a DNA Sequencer ABI 377 with the BigDye Terminator Cycle Sequencing Kit (Sangon Biotech Co., Ltd., Shanghai).

\section{Statistical analyses}

The genotypes, frequencies of gene and genotype, effective number of alleles, and gene heterozygosity were calculated (Nei and Li, 1979). The association between the genotypes of TLR4 and BHC and amount of tick infestation was performed with the least-squares method as applied in the generalized linear model procedure of SAS 8.2 according to the following: $y_{l}=\mu+G_{1}+e_{l}$, where $y_{l}$ is the observed value (BHC and number of infesting ticks), $\mu$ is the over mean of each observed trait, $G_{I}$ is the fixed effect of each genotype, and $e_{l}$ is the random error.

\section{RESULTS}

\section{Local skin reactions to tick infestation}

Red Angus with hypersensitivity to tick infestation displayed the strongest local skin reactions and allergic inflammation (Figure 1A). On the contrary, Brahman with stronger antitick capabilities terminated the inflammation more quickly than the other cattle breeds did, and the syndrome disappeared sooner on its skin (Figure 1B and C). BMY cattle varied the duration of the tick infestation load.
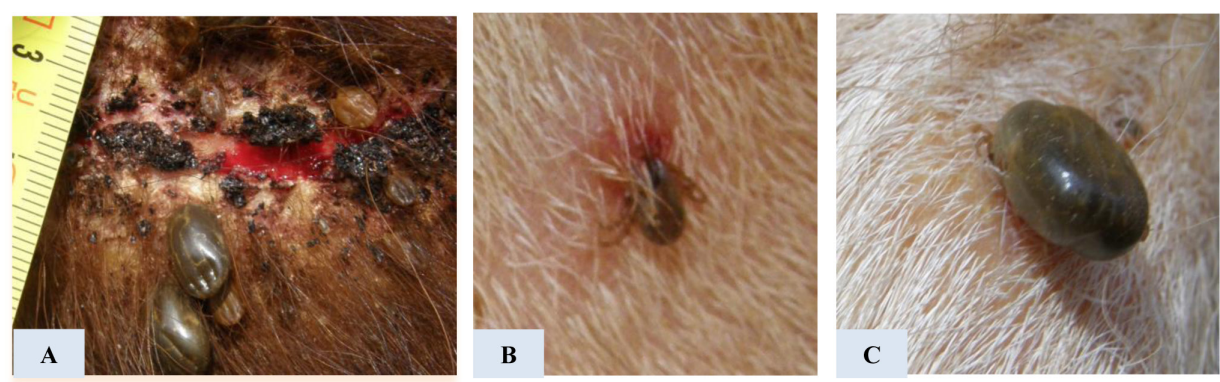

Figure 1. Different skin reactions after tick infestation. A. 'Tick sore' and permanent skin lesions after 6 weeks of tick load in Red Angus; B. Local skin inflammation near to the tick's mouthpart in the earlier stages (7 days) in Brahman; C. Resolution of inflammation of the final tick infestation in Brahman.

\section{Differences in tick weight and amount of $R$. microplus infestation}

Significant differences in tick weights and amounts between Brahman and Red Angus were found in the sum of fully engorged and half-engorged ticks $(\mathrm{P}<0.01)$. The corresponding values in Red Angus were significantly different from those in BMY cattle and Red Angus ( $\mathrm{P}$ $<0.05$; Table 1). Red Angus with tick infestation had lower BHC. BHC was higher when tick infestation was lower, as in Brahman, which showed a significantly negative correlation $(\mathrm{P}<$ 0.01 ; see Table 1). 
G. Zhao et al.

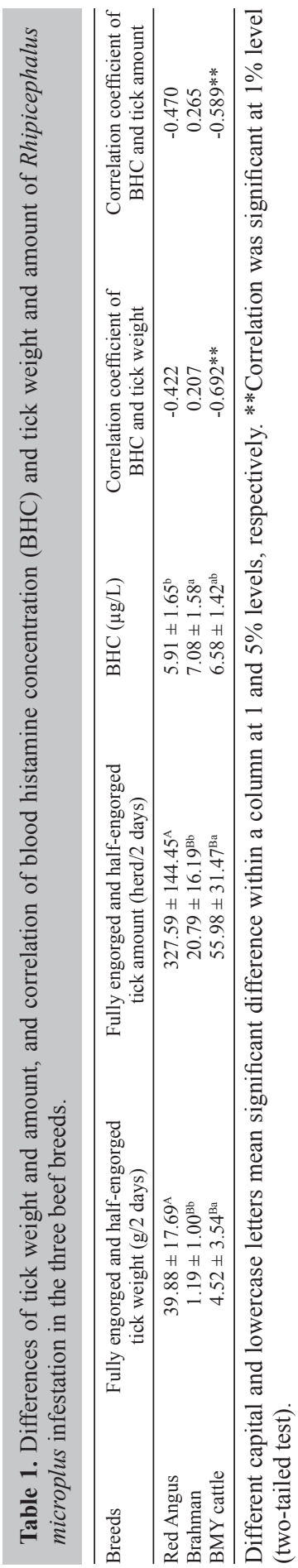




\section{Polymorphisms and genotypes of the TLR4 gene}

A 228-bp fragment of the TLR4 gene was amplified and sequenced. After SSCP analysis, four TLR 4 genotypes were defined in the samples. Four single nucleotide polymorphisms (SNPs) were also detected in the samples. Genotypes $\mathrm{AA}, \mathrm{AB}, \mathrm{BB}$, and $\mathrm{BC}$ were found in Brahman and BMY cattle, AA and AB in Red Angus, and AA in Simmental and Chinese Holstein. Three SNPs (535.A $>$ C, 546.T $>C$, and 605.T $>A$ ) were designated genotype AB, four novel SNPs (535.A $>$ C, 546.T $>$ C, 605.T $>$ A, and 618.G $>$ C) as BB, and one SNP $(618 . \mathrm{G}>\mathrm{C})$ as $\mathrm{BC}$ (Figures 2 and 3). The 535. $\mathrm{A}>\mathrm{C}$ and 546.T $>\mathrm{C}$ SNPs were synonymous mutations, whereas 605.T $>\mathrm{A}$ and 618.G $>\mathrm{C}$ generated missense mutations that caused Leu $\rightarrow \mathrm{Gln}$ and $\mathrm{Gln} \rightarrow$ His substitutions, respectively.

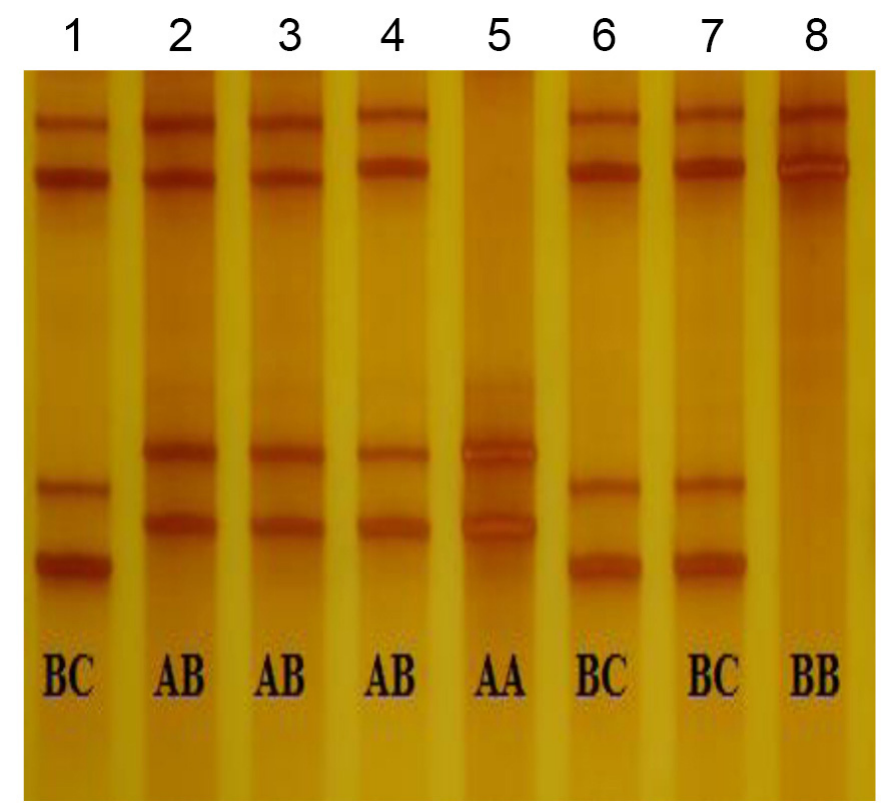

Figure 2. PCR-SSCP patterns of the TLR4 gene. Lane $5=$ genotype AA; lane $8=$ genotype BB; lanes 2,3 and $4=$ genotype $\mathrm{AB}$; lanes 1, 6 and $7=$ genotype $\mathrm{BC}$. No genotypes $\mathrm{AC}$ and $\mathrm{CC}$ were found in the samples.

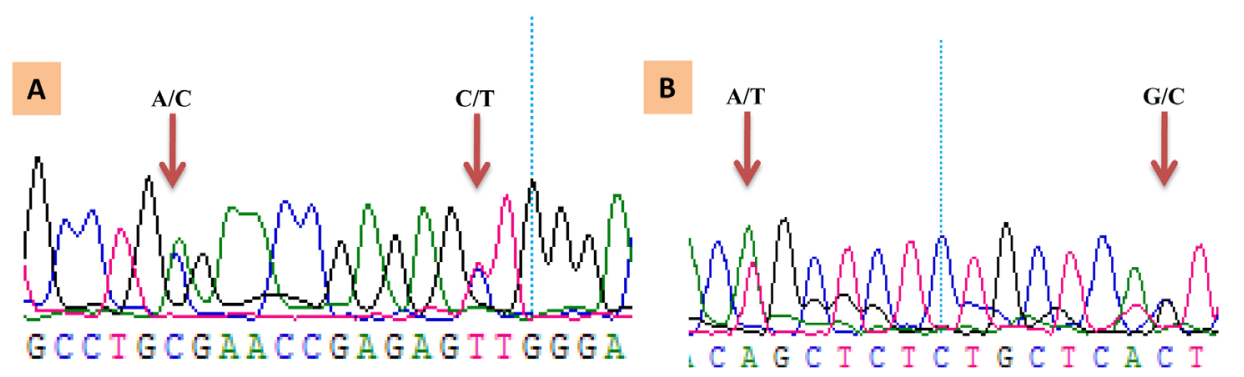

Figure 3. Sequencing images of the TLR4 gene. A. Single nucleotide polymorphisms (SNPs) at 535.A $>C$ and 546. T $>$ C; B. SNPs at 605.T $>$ A and 618.G $>$ C. 
Allele A was predominant in the 5 beef breeds, and allele $\mathrm{C}$ was infrequent. In Chinese Holstein and Simmental, AA was the only genotype detected. Genotype AB was the most predominant in BMY cattle (41.2\%), and genotype AA was distributed predominantly in Brahman and Red Angus (Table 2). The genetic polymorphic parameters of the TLR4 gene, including polymorphic information content (PIC), gene heterozygosity, and effective number of alleles, are shown in Table 2. PIC values in Brahman and BMY cattle ranged from 0.25 to 0.50 , suggesting an intermediate polymorphism, and BMY cattle showed the highest value with a frequency of 0.444 (see Table 2). The highest homogeneity occurred in Red Angus, which had the lowest PIC and gene heterozygosity values of 0.240 and 0.278 , respectively, in agreement with our previous studies (Qu et al., 2006). The TLR4 gene had higher variance in BMY cattle in accordance with the genetic progress made in its crossbreeding program.

\begin{tabular}{|c|c|c|c|c|c|c|c|c|c|c|c|}
\hline \multirow[t]{2}{*}{ Breeds } & \multirow[t]{2}{*}{$\mathrm{N}$} & \multicolumn{4}{|c|}{ Genotype frequencies (\%) } & \multicolumn{3}{|c|}{ Gene frequencies $(\%)$} & \multirow[t]{2}{*}{ PIC } & \multirow[t]{2}{*}{$H_{\mathrm{E}}$} & \multirow[t]{2}{*}{$N_{\mathrm{E}}$} \\
\hline & & $\mathrm{AA}$ & $\mathrm{AB}$ & $\mathrm{BB}$ & $\mathrm{BC}$ & A & B & $\mathrm{C}$ & & & \\
\hline Red Angus & 9 & 66.7 & 33.3 & 0.0 & 0.0 & 83.3 & 16.7 & 0.0 & 0.240 & 0.278 & 1.385 \\
\hline Brahman & 30 & 40.0 & 26.7 & 23.3 & 10.0 & 53.3 & 41.7 & 5.0 & 0.438 & 0.538 & 2.172 \\
\hline BMY cattle & 34 & 35.2 & 41.2 & 11.8 & 11.8 & 55.9 & 38.2 & 5.9 & 0.444 & 0.539 & 2.165 \\
\hline Simmental & 32 & 100.0 & 0.0 & 0.0 & 0.0 & 100.0 & 0.0 & 0.0 & - & - & - \\
\hline Chinese Holstein & 32 & 100.0 & 0.0 & 0.0 & 0.0 & 100.0 & 0.0 & 0.0 & - & - & - \\
\hline
\end{tabular}

$(-)=$ default values; $\mathrm{PIC}=$ polymorphic information content; $H_{\mathrm{E}}=$ expected heterozygosity; $N_{\mathrm{E}}=$ effective number of alleles.

\section{Association of TLR4 genotypes and BHC}

$\mathrm{BHC}$ values in Red Angus and BMY cattle with allele B were moderately higher, and Brahman with genotype BC displayed the highest level $(8.46 \mu \mathrm{g} / \mathrm{L})$. Overall, cattle with genotype AA had the highest tick infestation loads and tick weights; whereas those in cattle with genotype BB were significantly lower than those in cattle with genotype AA $(\mathrm{P}<0.05)$. The amount of tick infestation in animals with genotypes $\mathrm{AB}$ and $\mathrm{BC}$ was moderate. With respect to amount of tick infestation in BMY cattle and Red Angus, those with genotype AA displayed a significantly higher amount than those with genotype $\mathrm{AB}(\mathrm{P}<0.05$; Table 3$)$.

\begin{tabular}{|c|c|c|c|c|}
\hline Items & Genotypes & Red Angus & Brahman & BMY cattle \\
\hline \multirow[t]{4}{*}{$\mathrm{BHC}(\mu \mathrm{g} / \mathrm{L})$} & AA & $5.42 \pm 0.98^{b}$ & $7.04 \pm 1.81^{\mathrm{ab}}$ & $5.20 \pm 2.29^{\mathrm{Bb}}$ \\
\hline & $\mathrm{AB}$ & $6.88 \pm 2.52^{\mathrm{a}}$ & $7.27 \pm 1.10^{\mathrm{ab}}$ & $7.00 \pm 0.94^{\mathrm{Aa}}$ \\
\hline & $\mathrm{BB}$ & - & $6.34 \pm 1.38^{\mathrm{b}}$ & $7.16 \pm 1.08^{\mathrm{Aa}}$ \\
\hline & $\mathrm{BC}$ & - & $8.46 \pm 2.01^{\mathrm{a}}$ & $6.14 \pm 0.58^{\mathrm{ABab}}$ \\
\hline \multirow[t]{4}{*}{ Infected tick weight $(\mathrm{g})$} & $\mathrm{AA}$ & $44.68 \pm 17.78^{\mathrm{a}}$ & $1.63 \pm 1.31^{\mathrm{a}}$ & $5.99 \pm 1.32^{\mathrm{a}}$ \\
\hline & $\mathrm{AB}$ & $30.27 \pm 15.90^{\mathrm{b}}$ & $1.27 \pm 1.00^{\mathrm{ab}}$ & $3.37 \pm 1.55^{\mathrm{b}}$ \\
\hline & BB & - & $1.01 \pm 0.57^{\mathrm{b}}$ & $2.20 \pm 1.54^{\mathrm{b}}$ \\
\hline & $\mathrm{BC}$ & - & $1.07 \pm 0.59^{\mathrm{b}}$ & $5.80 \pm 1.44^{\mathrm{a}}$ \\
\hline \multirow[t]{4}{*}{ Infected tick amounts (herd) } & AA & $374.60 \pm 143.78^{\mathrm{A}}$ & $25.97 \pm 21.92^{\mathrm{a}}$ & $68.61 \pm 15.32^{\mathrm{Aa}}$ \\
\hline & $\mathrm{AB}$ & $233.57 \pm 109.07^{\mathrm{B}}$ & $20.53 \pm 16.27^{a b}$ & $47.76 \pm 9.87^{\mathrm{Bb}}$ \\
\hline & $\mathrm{BB}$ & - & $17.67 \pm 8.66^{\mathrm{b}}$ & $33.93 \pm 23.15^{\mathrm{Bc}}$ \\
\hline & $\mathrm{BC}$ & - & $21.10 \pm 7.89^{\mathrm{ab}}$ & $58.36 \pm 22.64^{\mathrm{Ab}}$ \\
\hline
\end{tabular}

$(-)=$ default values. Different capital and lowercase letters represent significant level at 1 and $5 \%$ in a column, respectively. 


\section{DISCUSSION}

Ticks have developed a diverse array of antihemostatic agents that are speculated to be essential for successful blood sucking (Andreotti et al., 2002). Oliveira et al. (2010) have summarized the six categories of active molecules from the salivary glands of ticks: 1) prostaglandin (Bowman et al., 1995); 2) histamine band proteins (Arocha-Pinango et al., 1999); 3) platelet aggregation inhibitor (Mans et al., 2002); 4) thrombin inhibitor (Liao et al., 2009); 5) antimicrobial protein (Lai et al., 2004b); and 6) an opioid peptide analog identified from neuroganglion, which is believed to inhibit algesthesia in the host (Lai et al., 2004a,b). The domain that mediates inflammation in the allergic reaction caused by these bioactive molecules is histamine. Injection of histamine causes defluxion of some of the ticks, whereas injection of callidin, E2, or seronine does not (Kemp and Bourne, 1980). Dermacentor reticulatus and other ticks secrete a homolog of histamine relief factor in their saliva, the nucleotide sequences of which displayed a homology ranging from 84.0 to $98.9 \%$. The protein family may be a desirable targeted antigen for the control of tick infestation (Mulenga and Azad, 2005). Given the important function of histamine, it could be an important candidate for transmitting the anti-tick capability of cattle compared with the other factors generated by tick infestation in the immunity system.

The levels of Boophilus microplus infestation showed that Brahman cattle with innate anti-tick capability from tropical zones were significantly stronger than Red Angus originated from temperate zones, suggesting that a smaller tick infestation could be a reflection of stronger bovine anti-tick capability, which may result from an inflammatory reaction in the host, hindering ingestion and slowing its pace in ticks. A significant negative correlation was identified between BHC level and amount of tick infestation in BMY cattle, with a correlation coefficient of $-0.692(\mathrm{P}<0.01)$, and similar results were found in Red Angus, with a correlation coefficient of $-0.470(\mathrm{P}<0.01)$. However, no significant correlation was found in Brahman, indicating that the cattle breeds had different inflammatory responses. Brahman and other breeds with stronger anti-tick capabilities might resist ticks by repairing their skin dermalstructure or secreting specific antigen and blood coagulation factors to resist the agents found in the salivary glands of ticks (Bechara et al., 2000; Zhao and Kong, 2000; Maritz-Olivier et al., 2007). These results demonstrated that the inflammatory reaction to the whole tick body was one of the most important responses that cattle displayed to tick infestation.

Cattle with lower susceptibility to tick infestation can acquire stronger tick resistance through the passive transfer of plasma from stronger cattle (Roberts and Kerr, 1976). Cattle with stronger tick resistance capability always display high BHC, which stimulates ticks and facilitates their leaving from the host (Kemp and Bourne, 1980). After injecting unfed larval extract of B. microplus, a cutaneous hypersensitivity test, into European and Indian cattle, Bechara et al. (2000) found that the preinfested European cattle showed a reaction within 10 min after injection. In contrast, the preinfested Indian cattle presented a response between 10 min and $1 \mathrm{~h}$ post-inoculation as well as a delayed reaction $72 \mathrm{~h}$ post-injection. Bioactive molecules in tick saliva have been shown to stimulate a TLR4 ligand, leading to increased secretion of interleukin-10 and initiate immune response (Oliveira et al., 2010). After a 6-week infestation with $B$. microplus, cattle that were more susceptible to tick infestation showed more obvious engorgement and granulocyte infiltrations at bite sites compared with those in cattle that were less susceptible to tick infestation; the host limited the inflammatory process, which 
contributed to the resolution of inflammation and wound healing (Constantinoiu et al., 2010). These results demonstrated that skin testing is informative for determining the susceptibility and resistance of cattle to ticks (Bechara et al., 2000).

A similar phenomenon was found in the present study. The level of tick infestation in Red Angus was associated with lower BHC level and stronger inflammation and hypersensitivity reactions at the bite sites. BMY cattle and Brahman with allele B had a lower level of tick infestation and higher BHC. Significant differences were found among cattle with genotypes $\mathrm{AA}, \mathrm{BB}$, and $\mathrm{AB}$, indicating that allele $\mathrm{B}$ of the TLR4 gene was significantly associated with $\mathrm{BHC}$ and tick resistance.

Feedlot-fed Holsteins in Nanjing were entirely free of tick infestation, whereas the Canadian Simmental cattle in the study had a 14-year history of tick infestation at Xiaoshao, Kunming. Genotype AA was the only genotype detected to these beef breeds. The results suggested that the bovine TLR4 gene with no or short history of tick infestation did not mutate. Red Angus were found with two genotypes, but genotype BB was absent. BMY cattle and their paternal Brahman displayed four genotypes; however, genotypes $\mathrm{AC}$ and $\mathrm{CC}$ have not yet been found. The frequency of allele B in BMY cattle was 38.2\% - close to that in Brahman. Therefore, allele B was apt to be inherited, and the fixation of allele B in a crossbreeding program would be quite effective for breeding tick resistance. The results seem to suggest that both alleles A and B are associated with tick susceptibility and resistance, respectively.

The potential function of allele $\mathrm{C}$ cannot be inferred from our findings, and more animals must be studied to detect the three $\mathrm{C}$ genotypes. We inferred that allele $\mathrm{B}$ of the TLR 4 gene is a candidate gene for tick resistance in beef breeding programs and an ideal molecular marker for tick-resistance breeding originating from paternal Zebu. BMY cattle are regarded as a newly successful crossbred beef breed with stronger tick resistance developed through the introduction of Zebu into tropical and subtropical zones in South China.

\section{ACKNOWLEDGMENTS}

Research supported by the General Program of Applied Basic Research of Yunnan Province (\#2011FB132), the National Key S and T Special Project (\#2012ZA024), the Key Technology for Efficient Transformation of Pasture-Livestock in Shangri-la Community, from the Special Fund for Agro-Scientific Research in the Public Interest (\#2012030028), and the Society Developmental Project of Yunnan Province, China (\#2008LA018).

\section{REFERENCES}

Abel B, Thieblemont N, Quesniaux VJ, Brown N, et al. (2002). Toll-like receptor 4 expression is required to control chronic Mycobacterium tuberculosis infection in mice. J. Immunol. 169: 3155-3162.

Aderem A and Ulevitch RJ (2000). Toll-like receptors in the induction of the innate immune response. Nature 406: 782-787.

Andreotti R, Gomes A, Malavazi-Piza KC, Sasaki SD, et al. (2002). BmTI antigens induce a bovine protective immune response against Boophilus microplus tick. Int. Immunopharmacol. 2: 557-563.

Arbour NC, Lorenz E, Schutte BC, Zabner J, et al. (2000). TLR4 mutations are associated with endotoxin hyporesponsiveness in humans. Nat. Genet. 25: 187-191.

Arocha-Pinango CL, Marchi R, Carvajal Z and Guerrero B (1999). Invertebrate compounds acting on the hemostatic mechanism. Blood Coagul. Fibrinolysis 10: 43-68.

Ausubel FM, Brent R, Kingston RE, Moore DD, et al. (1995). Short Protocols in Molecular Biology. 3rd edn. John Wiley and Sons, New York. 
Bechara GH, Morelli Júnior J and Szabó MP (2000). Skin test and tick immune status in susceptible and resistant cattle in Brazil. Ann. N. Y. Acad. Sci. 916: 570-575.

Bowman AS, Sauer JR, Zhu K and Dillwith JW (1995). Biosynthesis of salivary prostaglandins in the lone star tick, Amblyomma americanum. Insect Biochem. Mol. Biol. 25: 735-741.

Constantinoiu CC, Jackson LA, Jorgensen WK, Lew-Tabor AE, et al. (2010). Local immune response against larvae of Rhipicephalus (Boophilus) microplus in Bos taurus indicus and Bos taurus taurus cattle. Int. J. Parasitol. 40: 865-875.

Gao JL, Yin H and Luo JX (2004). Research status of immunological control of ticks. Chin. J. Vet. Sci. Tech. 34: 39-44.

Kemp DH and Bourne A (1980). Boophilus microplus: the effect of histamine on the attachment of cattle-tick larvae studies in vivo and in vitro. Parasitology 80: 487-496.

Lai R, Lomas LO, Jonczy J, Turner PC, et al. (2004a). Two novel non-cationic defensin-like antimicrobial peptides from haemolymph of the female tick, Amblyomma hebraeum. Biochem. J. 379: 681-685.

Lai R, Takeuchi H, Lomas LO, Jonczy J, et al. (2004b). A new type of antimicrobial protein with multiple histidines from the hard tick, Amblyomma hebraeum. FASEB J. 18: 1447-1449.

Liao M, Zhou J, Gong H, Boldbaatar D, et al. (2009). Hemalin, a thrombin inhibitor isolated from a midgut cDNA library from the hard tick Haemaphysalis longicornis. J. Insect Physiol. 55: 164-173.

Mans BJ, Louw AI and Neitz AW (2002). Evolution of hematophagy in ticks: common origins for blood coagulation and platelet aggregation inhibitors from soft ticks of the genus Ornithodoros. Mol. Biol. Evol. 19: 1695-1705.

Maritz-Olivier C, Stutzer C, Jongejan F, Neitz AW, et al. (2007). Tick anti-hemostatics: targets for future vaccines and therapeutics. Trends Parasitol. 23: 397-407.

McGuire K, Jones M, Werling D, Williams JL, et al. (2006). Radiation hybrid mapping of all 10 characterized bovine Toll-like receptors. Anim. Genet. 37: 47-50.

Mulenga A and Azad AF (2005). The molecular and biological analysis of ixodid ticks histamine release factors. Exp. Appl. Acarol. 37: 215-229.

Nei M and Li WH (1979). Mathematical model for studying genetic variation in terms of restriction endonucleases. Proc. Natl. Acad. Sci. U. S. A. 76: 5269-5273.

O'Kelly JC and Spiers WG (1976). Resistance to Boophilus microplus (Canestrini) in genetically different types of calves in early life. J. Parasitol. 62: 312-317.

Oliveira CJ, Carvalho WA, Garcia GR, Gutierrez FR, et al. (2010). Tick saliva induces regulatory dendritic cells: MAPkinases and Toll-like receptor-2 expression as potential targets. Vet. Parasitol. 167: 288-297.

Qu KX, Zhu FX, Wu GS, Nie L, et al. (2006). Genetic diversity and population structure of BMY and brahman cattle revealed by six microsatellite loci. Yi Chuan 28: 285-290.

Qu KX, Zhao G, Yang GR, Wen JK, et al. (2007). Selective breeding progress on BMY cattle. China Cattle Sci. 33: 18-21.

Qu KX, Huang BZ, Yang GR, He ZX, et al. (2012). Genetic diversity analysis of BMY cattle based on microsatellite DNA markers. Genetika 48: 522-528.

Reiling N, Hölscher C, Fehrenbach A, Kröger S, et al. (2002). Cutting edge: Toll-like receptor (TLR)2- and TLR4mediated pathogen recognition in resistance to airborne infection with Mycobacterium tuberculosis. J. Immunol. 169: 3480-3484.

Roberts JA and Kerr JD (1976). Boophilus microplus: passive transfer of resistance in cattle. J. Parasitol. 62: 485-488.

Wen JK (1996). A summary on tropical and sub-tropical beef crossbreeding combination and selective breeding in Yunnan. J. Yellow Cattle Sci. 22 (Suppl): 1-10.

Wen JK, Yang GR, Zhao KD, Wang AK, et al. (2003). The extension of reproduction and selective breeding in BMY cattle. Yunnan Anim. Husb. Vet. Med. 3: 1-4.

White SN, Kata SR and Womack JE (2003). Comparative fine maps of bovine toll-like receptor 4 and toll-like receptor 2 regions. Mamm. Genome 14: 149-155.

Yang SP, Yang GR, Wang Z, Zhang JC, et al. (2011). Preliminary report on the beef yield and characteristic from BMY cattle's hump. China Cattle Sci. 37: 6-9.

Zhao ZF and Kong FY (2000). A survey of tick-induced host immune response. Acta Parasitol. Med. Entomol. Sin. 7 : $115-120$. 